\title{
Patchiness in prey levels increases vulnerability of Critically Endangered Northern Bald Ibises Geronticus eremita on their Syrian breeding grounds
}

\author{
JEREMY A. LINDSELL, ADWAN H. SHEHAB and GUY Q. A. ANDERSON
}

\section{Summary}

A small colony of Northern Bald Ibis Geronticus eremita breeding in the Syrian desert is the only wild remnant of the eastern population of this 'Critically Endangered' species. Since its discovery in 2002, the colony has not increased in size despite being protected on the breeding grounds and exhibiting good productivity until recently. Although it appears that the population is being limited during migration and/or wintering, maintaining maximum breeding productivity is a priority for saving this colony to offset poor survival away from Syria. The ibises have a large home range but forage at a relatively small number of sites within it, despite having access to larger areas of apparently suitable habitat. We sampled potential prey using transects, pitfall traps and searches under stones at sites used by the birds to compare with unused sites. Analysis showed that used sites were twice as rich in vertebrate and invertebrate prey than the surrounding areas. Prey levels halved over the course of the breeding season, but we found that they remained higher in the preferred locations compared with the unused areas. Sites closer to the breeding cliff tended to have lower levels of prey available, which perhaps explained the long commutes that the adults undertook when foraging.

This work highlights the vulnerability of the birds at this site. Degradation of the patches they use could reduce food supply below critical levels and alternative sites may be hard for the birds to identify, being relatively scarce. The birds are also vulnerable to shortening of the season in which adequate food is available. There is already little time post-fledging to prepare for migration. Low food availability later in the season makes the birds dependent on key resources found around local reservoirs and these have failed recently. Breeding failures in 2008 and 2009 may have been mitigated by improved feeding conditions on the breeding area. The successful management of the site for ibises should include measures to improve their food security through range management, and possibly reservoir rehabilitation.

\section{Introduction}

Until recently, the entire global population of the 'Critically Endangered' Northern Bald Ibis Geronticus eremita was thought to breed along a narrow strip of coastline in Morocco where it is largely sedentary (BirdLife International 2009). The ecology of this population has been well studied and such understanding has underpinned the conservation programme to date (Bowden et al. 2008). The Middle East population was thought to be extinct in the wild since 1989 until a small colony was rediscovered in Syria in 2002 (Serra et al. 2004). Although these birds have been closely monitored, their ecology is still poorly understood. The eastern population differs significantly from the Moroccan population in being migratory (Collar and Stuart 1985, Bowden 
et al. 2003) but it was not until very recently that the migration routes, staging and wintering sites were described (Lindsell et al. 2009). Some progress has been made in describing their ecology on the breeding grounds (Serra et al. 2008, 2009) but there remains much to be understood about their requirements and the implications for site management and protection.

The remaining fully migratory wild birds in Syria provide a crucial resource if plans to reestablish this species in the region are to succeed (Boehm et al. 2007). Since its discovery however, the Syrian colony has not grown, despite protection at the breeding site (Serra et al. 2009). An initial three breeding pairs declined after two years to just two pairs and remained at this level (accompanied by 1-4 non-breeding subadults) until 2009. It seems likely that the chief constraints to population growth are during the migration and wintering period (mortality in Syria amongst fully grown birds has been very rare). However, to improve the prospects of recovery it remains a high priority to ensure that conditions on the breeding site remain as favourable as possible to maximise productivity and compensate for high mortality rates at other times of year. One key condition for high productivity is the availability of good quality foraging habitat to support the colony, but our understanding of their foraging habitat requirements in Syria is currently limited. Quantification of habitat conditions has been important in the conservation of numerous bird species, including other ibises (Sozer and Nijman 2005, Li et al. 2009). The foraging habitat requirements of Northern Bald Ibis in Morocco have been well described and consist of semi-natural steppe, cultivation and fallows of various ages with a preference for older fallow and steppe, in particular areas of c. $30 \%$ herbaceous (as opposed to shrub) cover (Bowden et al. 2008, Rice et al. 2002). These areas contained high densities of lizards (Aghnaj et al. 2001).

The ibises in Syria occupy an area of degraded steppe in the south of the country between February and July. They nest on high cliffs at either one of two sites, c.1o km apart. The area over which they range to forage is large $\left(c .230 \mathrm{~km}^{2}\right)$ but within that area, the patches they use regularly are small and remain the same from year to year (Serra et al. 2008). Two patches are close to the breeding cliffs but the other is $30-35 \mathrm{~km}$ away. Therefore, the birds often make lengthy flights in order to provision themselves and their chicks particularly later in the season (Serra et al. 2008). The reasons why these particular patches are used so regularly are not known but in this paper we investigate whether it is the result of prey availability. If the food supply in these patches is much better than in the overall landscape, the birds would be particularly vulnerable to degradation in these patches since they may be unable to forage effectively elsewhere. Knowing this would present an opportunity to improve the status of the colony if conditions in these patches could be recreated elsewhere. It has also been observed that the patches are used in a temporal progression suggesting the influence of a seasonal effect, the importance of which is unknown (Serra et al. 2008).

We investigated prey availability in these key patches, comparing it with similar areas nearby, but which were unused by the birds. Northern Bald Ibis feed on a variety of vertebrate and invertebrate prey including lizards, geckos, scorpions, ants, orthopterans and coleopterans (Bowden et al. 2008, Serra et al. 2008). We therefore used a range of sampling methods to compare prey abundance in used and unused areas, test whether prey abundance varied between the key patches used by the ibises and investigate the nature of seasonal changes in prey abundance.

\section{Methods}

The study was conducted in the Bald Ibis Reserve in the Syrian Badia $20 \mathrm{~km}$ north of the city of Palmyra $\left(34.60^{\circ} \mathrm{N} 38.25^{\circ}\right.$ E) in south central Syria (Figure I) between April and July 2008. Three main localities within the reserve regularly visited by foraging ibises in each year since 2002 were selected (see Serra et al. 2008). Site A was a flat stony area on hard soil with small wadi beds and sand sheets formed by wind action. Dominant vegetation was Syrian Rue Peganum harmala but with less than $1 \%$ cover. Other plants included Lavender Cotton Achillea fragrantissima, Sinai 
Meadow Grass Poa sinaica and Articulate Saxaul Haloxylon articulatum. This site was adjacent to the active breeding cliff in 2008. Site B was an arid area with hard soil and few stones and a mixture of wide flat areas and relatively deep canyons. Vegetation cover was generally less than $1 \%$, but reached 10\% in some other places, where Syrian Glasswort Anabasis syriaca was the dominant species. Other plants included $H$. articulatum and $P$. sinaica. This site was close to a breeding cliff used in other years. Site $\mathrm{C}$ was a flat area with loose soil and few stones. Vegetation cover was less than $1 \%$ and predominantly $A$. syriaca, $H$. articulatum, Saltwort Salsola volkensii and P. sinaica. All three sites were bordered by rocky hills on at least one side.

The climate in the area is dry throughout the year but with very hot summers and cold winters. Mean annual rainfall for Palmyra (1958-2000) was $127 \mathrm{~mm}$ with dry years having as little as $50 \mathrm{~mm}$ (Palmyra Meteorological Station). Mean monthly maximum temperatures for 1998-2007 were over $40^{\circ} \mathrm{C}$ in June and July, whilst mean monthly minima were below $-3^{\circ} \mathrm{C}$ in December and January (Talila Reserve Meteorological Station). The year of this study was exceptionally dry and hot.

Since the ibis take their prey from the ground, from plants and by probing, we used a variety of active and passive sampling methods to ensure main prey types were represented. For each of the three localities used by the birds, we placed three plots $(200 \times 200 \mathrm{~m})$ in positions representative of the general area. Three comparison plots were placed in adjacent areas (at least 1,00o m away) that matched in general topography, elevation and ground cover (Sutherland and Green 2004) but were not known to have been used by the ibises in the previous three years according to local wardens. Within each plot, three methods were used to assess food availability. 1) Transects were walked around the outer boundary of the plot once every two weeks rotating the visits to avoid confounding site with time of day. All vertebrates and invertebrates observed were identified as far as possible and counted using Distance methods (Buckland et al. 2001); temperature and time of day were also recorded. A total of 153 transect surveys of $800 \mathrm{~m}$ each were undertaken in the four localities between 11 April and 24 July; 2) five dry pitfall traps (plastic cups, $13 \mathrm{~cm}$ diameter $X$ $15 \mathrm{~cm}$ depth) were set at $50 \mathrm{~m}$ intervals along the eastern side of each plot. The trap contents were counted every 2-8 days then released nearby (some specimens were collected for identification); 3 ) twenty stones (15-40 cm long axis) in or near each plot were carefully lifted and the potential prey

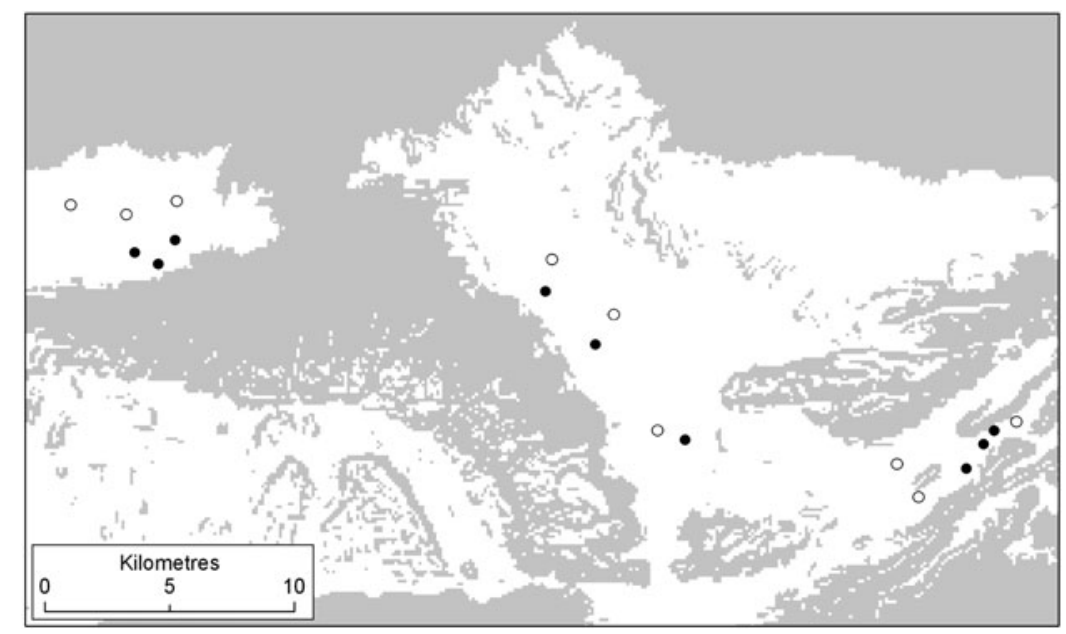

Figure 1 . Map of study area showing distribution of sample plots in foraging sites (filled circles) and avoided sites (open circles). Sites A, B and C are arranged from left to right. Grey areas show land outside the normal range of altitude and slope utilised by the birds. The breeding cliff used in the study year was close to the easternmost points. A second site used in some years is close to the central points. 
under each was identified and counted. This was done every two weeks each time sampling different stones.

\section{Statistical analysis}

We investigated the association of prey abundance with usage by the ibises, locality, and season, using mixed models with random effects (SAS v. 9.1; SAS Inc. 2003). Only invertebrate data were analysed from pitfall traps because many reptiles could have escaped the traps. The counts for each set of 20 stones were summed and the counts from pitfall traps on the same plot were summed for each trapping period and divided by the number of exposure days. Counts from the transects and stones were modelled with negative binomial errors because the data were too overdispersed to use Poisson errors. Pitfall trapping rates were modelled with Gamma errors. Plot or transect was specified as a random effect. The significance of individual effects was assessed using Type III sums of squares. The agreement between the three sampling methods for invertebrates was assessed by correlating the mean transect encounter rate, the mean count per trap day and the mean count per stone search for each of eight equal-length time periods throughout the season.

Distance software (Thomas et al. 2006) was used to estimate the density of prey from the transect surveys. Group data were pooled into $1 \mathrm{~m}$ intervals and truncated at $5 \mathrm{~m}$. AIC was used to select the preferred model.

\section{Results}

A summary of sampling effort and raw counts from the three sampling methods is given in Table 1 . A strong effect of both time of day and temperature (and both quadratic terms) on vertebrate encounters was found (Figure 2) confirming that scheduling of transect survey times was justified. Distance analysis of all data gave a mean vertebrate density of 6.9 ha $^{-1}$ (95\% CI: 5.2-9.2) and I48.1 ha ${ }^{-1}(99.2-217 \cdot 3)$ for invertebrates.

\section{Used versus unused}

Prey levels of all types encountered on transects were $30.1 \%$ higher in plots used by ibises $\left(\mathrm{F}_{1,140}=\right.$ 16.32, $P<$ o.0001) after accounting for temperature and season. Pitfall trapping rates were $81.8 \%$ higher in plots used by the ibises $\left(\mathrm{F}_{1,14.06}=7.44, P=0.02\right)$ after accounting for site and season effects. When comparing the mean pitfall trap rate between used and unused sites for each site in each week, in 39 out of 46 such comparisons $(84.8 \%$ ) the rate was equal or higher in the used plots. No significant difference between used and unused sites was noted for prey found under stones $\left(\mathrm{F}_{1,137}=0.26, P=0.61\right)$.

\section{Seasonal effect}

The transects, pitfalls, and stone searches all showed a seasonal decline in prey capture rates across all sites. Date had a significant explanatory effect on transect encounter rate for invertebrates $\left(\mathrm{F}_{1,135}=22.46, P<0.0001\right.$; Figure 3$)$ though not vertebrates $\left(\mathrm{F}_{1,136}=0.57, P=0.45\right)$ after accounting for site, temperature and time of day. Invertebrate detections declined by $70.0 \%$ during the course of the study. Pitfall contents declined $47.7 \%$ overall with trapping date but this varied by site as indicated by a significant interaction between date and site $\left(\mathrm{F}_{2,251.1}=12.99, \mathrm{P}<\right.$ O.01; Figure 4). Prey found under stones declined with date, by $92.7 \%$ overall, and again there was an interaction with site $\left(\mathrm{F}_{2,138}=3.18, P=0.04\right)$.

\section{Site effect}

Overall prey abundance tended to vary significantly between sites. For transect data, vertebrates showed a significant site effect $\left(\mathrm{F}_{2,137}=7.78, \mathrm{P}<0.0006\right)$ with site $\mathrm{B}$ having the highest levels 


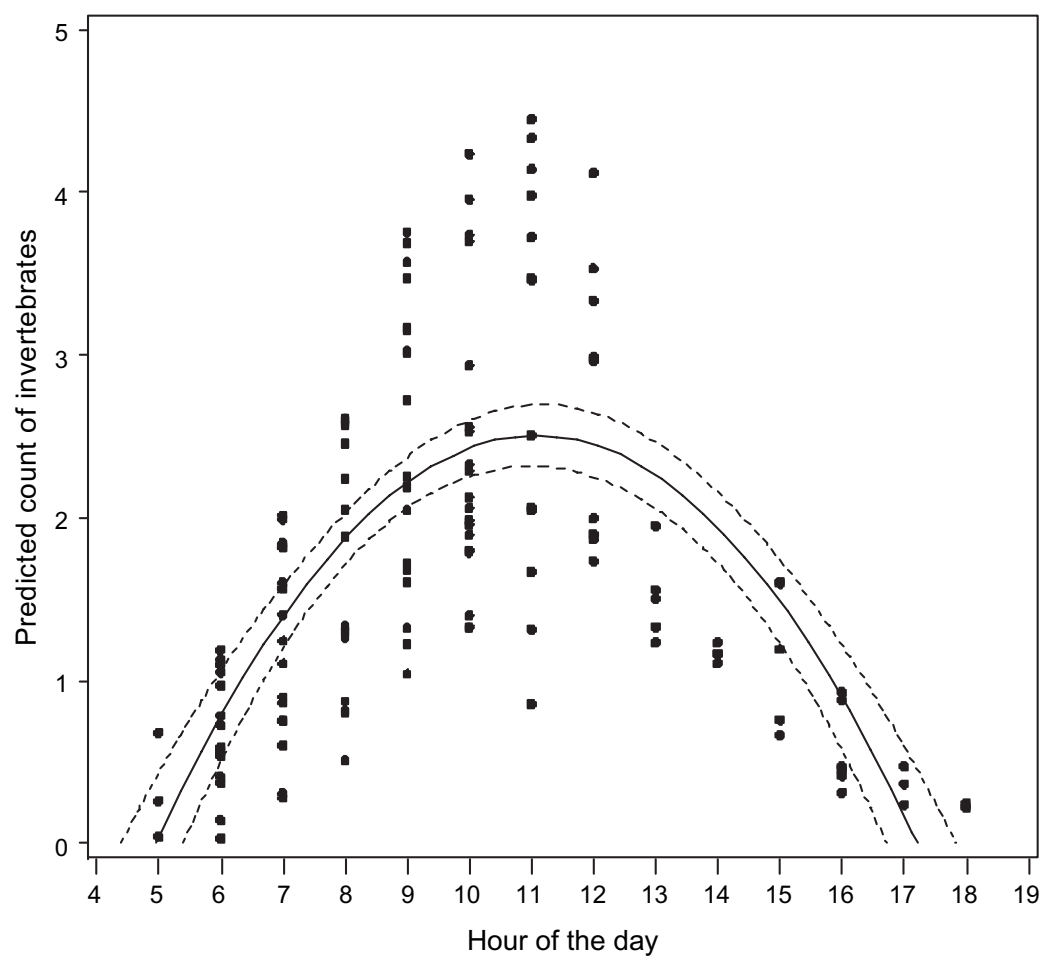

Figure 2. Variation in vertebrate counts with time of day on transects. Data points are predicted values from a GLMM including hour, hour ${ }^{2}$, temperature, temperature ${ }^{2}$ and site. The fitted line is a quadratic regression line with $95 \%$ confidence intervals.

and site $\mathrm{C}$ the lowest, after adjusting for time of day and temperature. Invertebrate data did not vary significantly by site. For the pitfall traps, there was a strong effect of site $\left(\mathrm{F}_{2,197}=16.99\right.$, $P<0.0001$ ) but, as observed above, the interaction between site and date was also significant. Overall, site C had the highest levels (3.43 individuals per trap day), site B intermediate (2.69) and site A the lowest levels (1.73) and the seasonal decline was strongly negative in site C and B, but weakly positive in site A. The prey under stones also varied by site but as noted above, this also interacted with date.

The good accordance between the different methods in these results was reflected in direct correlation of the three methods for the time periods in which they overlapped (Table 2).

\section{Discussion}

Intensive sampling of potential prey of Northern Bald Ibis in the Syrian steppe has revealed spatial and seasonal variations that account, to some degree, for the site selection and seasonal

Table 1. Summary of effort and raw results from three methods of sampling potential prey of Northern Bald Ibis.

\begin{tabular}{llcc}
\hline Method & Effort & Invertebrate $n$ & Vertebrate $n$ \\
\hline Transects & $122,400 \mathrm{~m}$ & 794 & 276 \\
Pitfalls & 90 traps $\times 19$ episodes & $20,179(17$ families $)$ & 198 (9 species $)$ \\
Stones & 3,245 stones & $5,466(12$ families $)$ & $50(6$ species $)$ \\
\hline
\end{tabular}




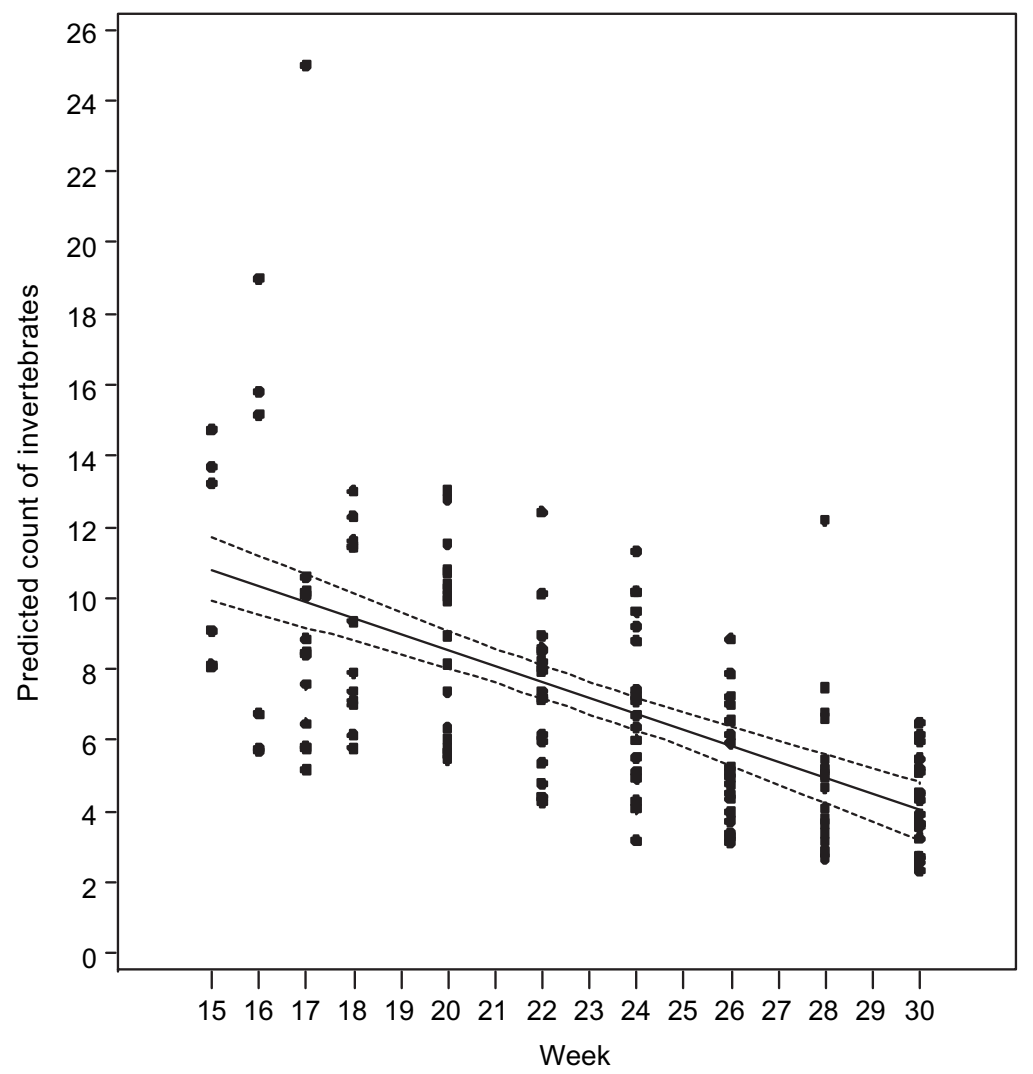

Figure 3. Variation in prey counts (vertebrates and invertebrates together) on transects during the season. Data points are predicted values from a GLMM including week (week 15 being 15-21 April), temperature and usage by ibises. The fitted line is linear regression with $95 \%$ confidence intervals shown.

patterns in movement observed in the birds themselves. The evidence presented highlights their vulnerability to change both from disturbance and degradation but also from climatic processes that might influence the period of food availability.

The patches used by the ibises had higher prey abundance than the surrounding areas, indicating that preferred prey levels were not ubiquitous despite the apparent physical uniformity of the landscape. This suggests that the ibises are vulnerable to landuse change, disturbance or degradation since alternative high value sites will be relatively scarce and possibly unknown to them. Threats from disturbance are real since the reserve overlaps with an important dry season grazing area for Bedouin pastoralists, and one key patch (site C) (Serra et al. 2008) lies within the exploration zone for an oil concession. Considerable effort was made in 2008 to ensure that oil prospecting activities did not alter or damage the patch. The importance of these key resources highlights the need to ensure protection of a network of sites within the wider reserve. Site $C$ was most distant from core protection activities around the breeding cliff, but is crucial since it provides foraging at the most demanding time of year. The breeding sites are not necessarily located where the best food resources are, so in situ protection of the Syrian birds requires attention to both. This underlines the importance of the Desert Commission's current efforts to ensure such protection. 


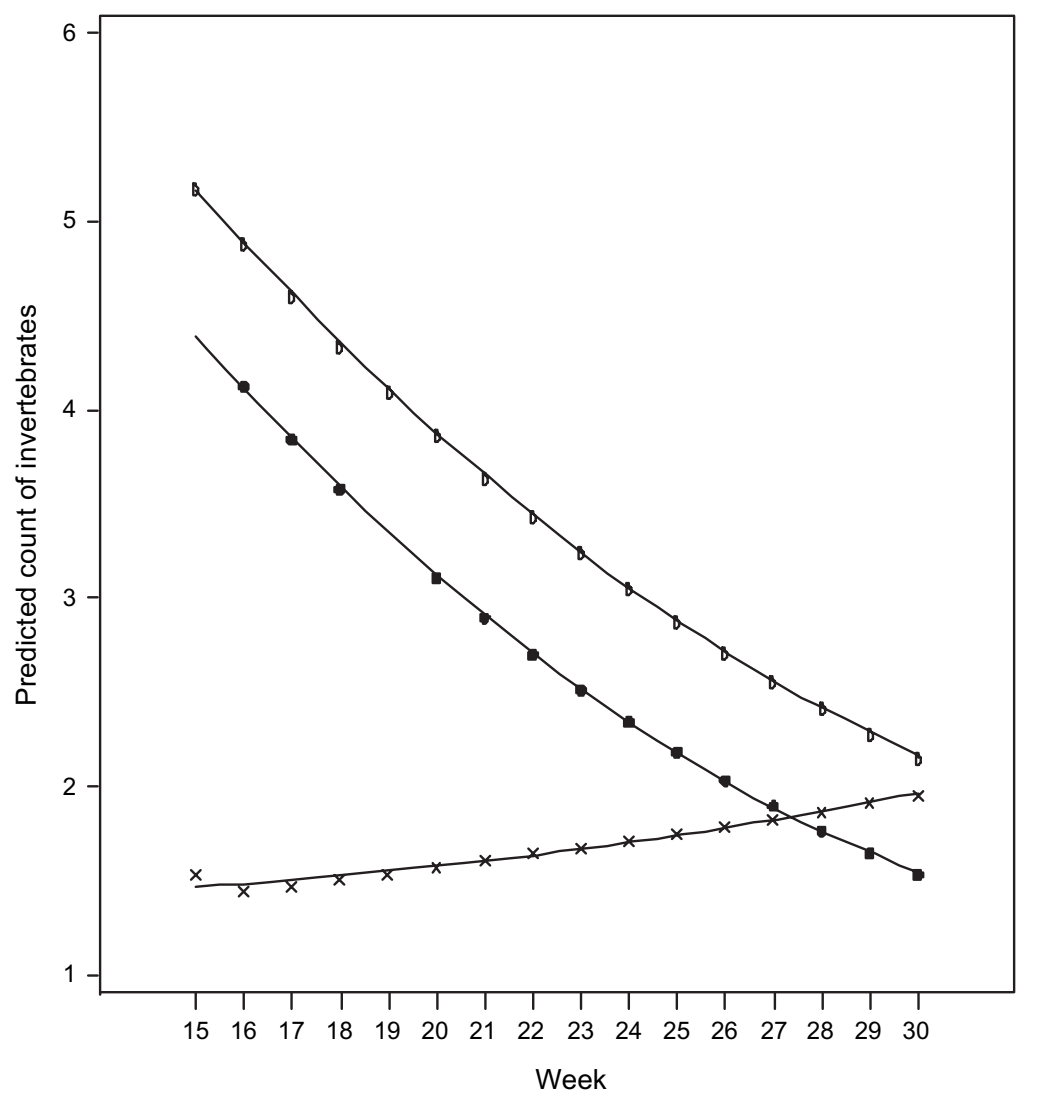

Figure 4. Variation in pitfall invertebrate capture rates during the season. Data points are weekly means of predicted values from a GLMM of pitfall counts modeled with site, usage, setdate (week 15 being $15-21$ April) and set-date* usage interaction. The fitted lines are quadratic regression lines. $\mathrm{X}=$ site $\mathrm{A}$, filled circle $=$ site $\mathrm{B}$, open circle $=$ site $\mathrm{C}$.

On all measures, prey abundance declined significantly over time, with the two most important foraging areas showing declines of between half and two thirds over the course of the season. This has important implications for the timing of breeding. The birds arrive in Syria in February and early March, making them one of the earliest arriving migrants, and commence breeding almost immediately. Even so, fledging dates are not until early to mid-June. This means that there is a period of about four weeks before they migrate in mid-July to acquire suitable physical condition. The early departure date may now be explained by low food availability in the breeding area and could well be contributing to the observed poor post-dispersal survival in juveniles. It also means that prey levels are declining just as the nutritional requirements of the birds are increasing. By contrast, Bowden et al. (2008) found no seasonal variation in detectability of lizards in Morocco where the ibises are resident (though they did find a drop in beetle numbers in the non-breeding season). The more distant feeding site is used especially during this pre-departure period, highlighting again the importance of its elevated prey levels.

The short breeding period makes the ibises particularly vulnerable to any further reduction in that time brought about by landuse or climate change. There are other food resources used by the ibises from time to time such as young amphibians taken on the shores of reservoirs (Serra et al. 2008). In 2008 all these reservoirs dried out so this resource was unavailable. The birds moved to 
Table 2. Correlation between three methods of sampling of Northern Bald Ibis invertebrate prey over the course of the birds' breeding season. Season was divided into 8 equal length time periods and mean transect encounter rate, mean count per trap day and mean count per stone search was calculated for each period.

\begin{tabular}{llll}
\hline Comparison & $n$ & Pearson $r$ & $P$ \\
\hline Transect * Pitfall & 8 & 0.67 & 0.07 \\
Transect ${ }^{*}$ Stones & 8 & 0.82 & 0.01 \\
Pitfall * Stones & 8 & 0.77 & 0.03 \\
\hline
\end{tabular}

an area some $70 \mathrm{~km}$ to the west of the breeding site presumably because their breeding attempts failed. We therefore sampled this site and found invertebrate levels in the pitfall traps to be very low compared with the other three sites, but vertebrate encounter rates on the transects somewhat higher (2.01 versus $3.06 \mathrm{~km}^{-1}$ ) but not significantly so. The use of this site was probably more influenced by the presence of water in a nearby reservoir since Northern Bald Ibis is also dependent on a water supply for drinking (Smith et al. 2008). It would probably take only small changes in land use or climate to alter the availability of water in the landscape or to accelerate the seasonal decline in prey species and shorten the effective season available to the birds to breed. This would make it impossible for them to breed, raise and fledge young in time to undertake a successful southward migration of c.3,00o km.

Although our work highlights the vulnerability of the site, it also presents an opportunity for management. If reliable predictors of prey abundance can be established, it may be possible to manage the site to increase food supply in preferred foraging areas. Vegetation cover is the most likely determinant of prey levels (Bowden et al. 2008), in turn determined by climate and grazing levels (Milchunas and Lauenroth 1993, Bowden et al. 2008, Louhaichi et al. 2009). Managing grazing levels to maintain optimal vegetation cover will be important since there can be tradeoffs in sward height between prey abundance and access. Grazing exclosures in the nearby Talila Reserve demonstrate that vegetation can recover to levels that may be too high and/or dense for Northern Bald Ibis (pers. obs.). The optimum level of grazing is currently unknown and in urgent need of research so that the reserve can be more carefully managed for the ibises. Changes in grazing intensity could be used to improve food supply throughout the reserve, thus reducing dependence on the current key patches, reducing foraging time when provisioning chicks and lengthening the time available for breeding and pre-migration.

Management intervention to improve conditions in the reserve seems all the more important in the light of recent breeding failures. In 2008 and 2009 no chicks were fledged from the colony. Although the causes of these failures are not certainly known, indications from 2008 at least were that chick starvation was the cause. Both years were very dry and the adult birds spent long periods away from the nests presumably because food was scarce. Had foraging conditions in nearby areas been more favourable then the likelihood of such failure would surely have been lower.

It is clear that for the Syrian ibises, habitat conditions on the breeding ground are far from robust, being patchy, restricted in area and subject to marked seasonal declines and annual variations. Changes in habitat were probably important drivers of the long term decline of this species over the last four centuries (Collar and Stuart 1985) and availability of suitable habitat is considered an important limiting factor for the Moroccan population today (Bowden et al. 2008). It seems that the small population in Syria survives in a landscape that is marginal in quality and vulnerable to change. Changes in land management that improve their food supply could lead to increased breeding productivity to offset poor survival away from the breeding site though the prospects for this population are looking increasingly bleak.

\section{Acknowledgements}

We would like to thank the Syrian authorities for facilitating this study, namely Prof. Adel Safar, Minister of Agriculture and Agrarian Reform, Eng. Ali Hamoud, Director General of the General 
Commission of Al Badia Development and Management; Dr A. Kanani and the administration of Al Talila Reserve; Eng. Abd Al Khalek Asaad and Samer Saoud. Many thanks are extended to the guards and rangers of Bald Ibis reserve namely Mr. Ahmed Jaber, Mohammed Ibrahim, Suleman Jkhaidem, Sultan Naglan and Faraj Al Bustan. Many thanks to Dr. Ahmed K. Bader for help with identification of prey items. Sharif Jbour of BirdLife Middle East was instrumental in the implementation of this work. We also acknowledge the valuable input through various discussions and advice of Lubomir Peske, Prof. Zuhair Amr, Gianluca Serra and Chris Bowden. Comments from Paul Donald, Paul Buckley, Juliet Vickery, Ken Smith, Jorge Orueta and Imad Cherkaoui greatly improved this manuscript. This research was funded by the Royal Society for the Protection of Birds.

\section{References}

Aghnaj, A., Smith, K. W., Bowden, C. G. R. and Ribi, M. (2001) Studies of the feeding ecology and habitat use of Northern Bald Ibis, Geronticus eremita, in the SousMassa National Park, Morocco. Ostrich suppl. 15: 197 .

BirdLife International. (2009) Species factsheet: Geronticus eremita. Downloaded from http://www.birdlife.org on ${ }_{15} / 6 /$ 2009.

Boehm, C., Bowden, C. G. R., Jordan, M. and King, C. (2007) Northern Bald Ibis conservation and reintroduction workshop. Sandy, UK: RSPB.

Bowden, C. G. R., Aghnaj, A., Smith, K. W. and Ribi, M. (2003) The status and recent breeding performance of the critically endangered Northern Bald Ibis Geronticus eremita population on the Atlantic coast of Morocco. Ibis 145: 419-431.

Bowden, C. G. R., Smith, K. W., Bekkay, M. E. L., Oubrou, W., Aghnaj, A. and Jimenez-Armesto, M. (2008) Contribution of research to conservation action for the Northern Bald Ibis Geronticus eremita in Morocco. Bird Conserv. Int. 18: S74-S9o.

Buckland, S. T., Anderson, D. R., Burnham, K. P., Laake, J. L., Borchers, D. L. and Thomas, L. (2001) Introduction to distance sampling: estimating abundance of biological populations. Oxford, UK: Oxford University Press.

Collar, N. J. and Stuart, S. N. (1985) Threatened birds of Africa and related islands. Cambridge, UK and Gland, Switzerland. ICBP.

Li, X. H., Tian, H. D. and Li, D. M. (2009) Why the crested ibis declined in the middle

twentieth century. Biodivers. Conserv. 18: 2165-2172.

Lindsell, J. A., Serra, G., Peske, L., Abdullah, M. S., al Qaim, G., Kanani, A. and Wondafrash, M. (2009) Satellite tracking reveals the migration route and wintering area of the Middle East population of Critically Endangered northern bald ibis Geronticus eremita. Oryx 43: 329-35.

Louhaichi, M., Salkini, A. K. and Petersen, S. L. (2009) Effect of small ruminant grazing on the plant community characteristics of semiarid Mediterranean ecosystems. Int. J. Agric. Biol. 11: 681-689.

Milchunas, D. G. and Lauenroth, W. K. (1993) Quantitative effects of grazing on vegetation and soils over a global range of environments. Ecol. Monogr. 63: 327-366.

Rice, P. M., Aghnaj, A., Bowden, C. G. R., Smith, K. W., Fox, H. R. and Moore, H. M. (2002) Te landscape ecology of the Northern Bald Ibis Geronticus eremita in the Sous-Massa National Park, southern Morocco. Pp. 264-272 in D. Chamberlain and A. Wilson, eds. Avian landscape ecology: pure and applied issues in the largescale ecology of birds. Proceedings of the eleventh annual IALE (UK) conference, University of East Anglia, 10-13 September 2002. International Association for Landscape Ecology.

SAS Inc. (2003) SAS v9.1. Cary, NC: SAS Institute Inc.

Serra, G., Abdallah, M., Assaed, A., Abdallah, A., Al Qaim, G., Fayad, T. and Williamson, D. (2004) Discovery of a relict breeding colony of northern bald ibis Geronticus eremita in Syria. Oryx 38: 106-8. 
Serra, G., Abdallah, M. S. and al Qaim, G. (2008) Feeding ecology and behaviour of the last known surviving oriental Northern Bald Ibises, Geronticus eremita (Linnaeus, 1758), at their breeding quarters in Syria. Zool. Middle East 43: 55-68.

Serra, G., Peske, L., Abdallah, M. S., al Qaim, G. and Kanani, A. (2009) Breeding ecology and behaviour of the last wild oriental Northern Bald Ibises (Geronticus eremita) in Syria. J. Ornith. 150: 769-782.

Smith, K. W., Aghnaj, A., Bekkay, M. E. L., Oubrou, W., Ribi, M., Armesto, M. J. and Bowden, C. G. R. (2008) The provision of supplementary fresh water improves the breeding success of the globally threatened Northern Bald Ibis Geronticus eremita. Ibis 150: $728-734$.
Sozer, R. and Nijman, V. (2005) Effects of ENSO-induced forest fires and habitat disturbance on the abundance and spatial distribution of an endangered riverine bird in Borneo. Anim. Conserv. 8: 27-31.

Sutherland, W. J. and Green, R. E. (2004) Habitat assessment. in W. J. Sutherland, I. Newton and R. E. Green, eds. Bird ecology and conservation: a handbook of techniques. Oxford, UK: Oxford University Press. Thomas, L., Laake, J. L., Strindberg, S., Marques, F. F. C., Buckland, S. T., Borchers, D. L., Anderson, D. R., Burnham, K. P., Hedley, S. L., Pollard, J. H., Bishop, J. R. B. and Marques, T. A. (2006) Distance 5.0, release 2. St Andrews, UK: University of St Andrews, Research Unit for Wildlife Population Assessment. http://www.ruwpa, st-and.ac.uk/distance/

JEREMY A. LINDSELL*, GUY Q. A. ANDERSON

The Royal Society for the Protection of Birds, The Lodge, Sandy, Beds SG19 2DL, U.K.

\section{ADWAN H. SHEHAB}

General Commission for Scientific Agricultural Research, Douma, P. O. Box 113, Damascus, Syria.

${ }^{*}$ Author for correspondence; e-mail: jeremy.lindsell@rspb.org.uk

Received II November 2009; revision accepted 15 July 2010;

Published online 3 November 2010 